\title{
Britain ponders scrapping 200-year-old census
}

Potential overhaul would yield surveys that are more frequent but less detailed.

\section{Daniel Cressey}

23 September 2013

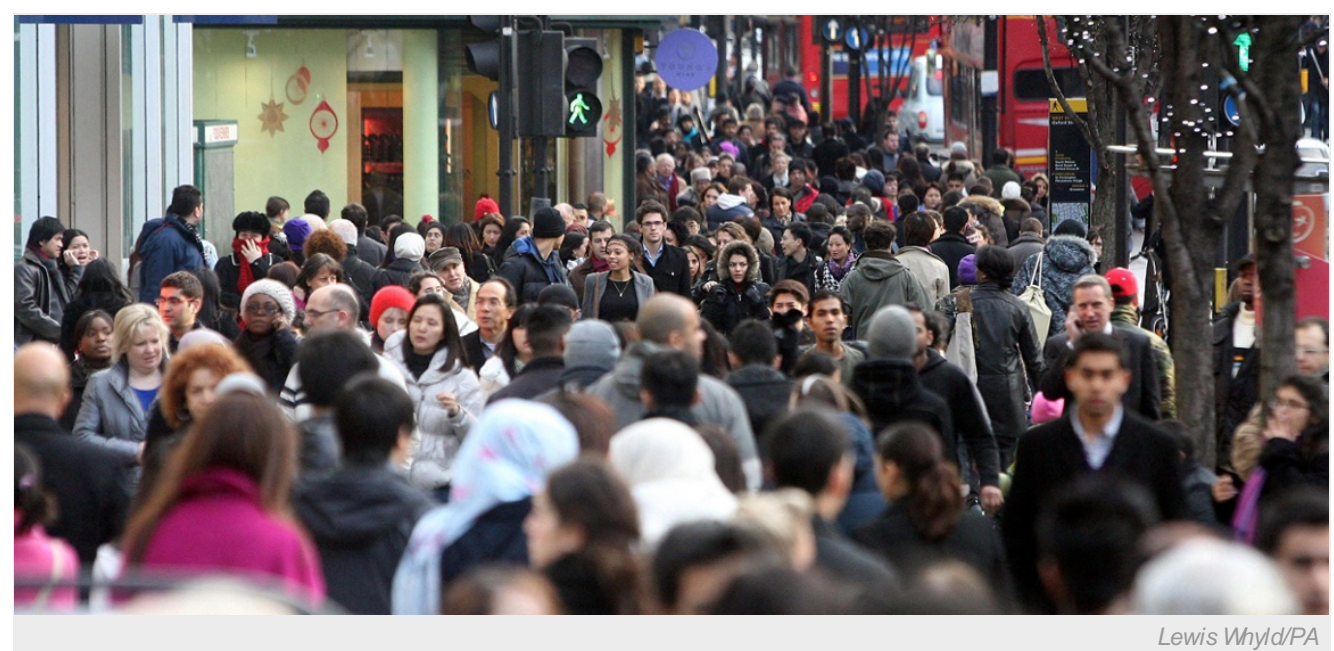

The UK government might stop trying to get an exact tally of the people living in England and Wales and rely instead on partial surveys and statistical estimates.

Researchers are being asked to weigh in on whether a census that has run in the United Kingdom since the early nineteenth century should be scrapped in its current guise - a proposal that has put some people on edge.

People in Britain have been asked to provide census data every ten years since 1801, with the last survey in 2011, stopping only once for the Second World War. But a consultation launched today for England and Wales by the Office for National Statistics (ONS) in Newport, UK, could result in radical changes to both the census and the data it provides to researchers.

One proposed system would instead use information from national databases to produce most of the census data, which would then be topped up by much smaller surveys of only about $4 \%$ of the population each year. This would provide data such as ethnicity and languages spoken.

In another option that is still on the table, the ONS would send a compulsory questionnaire to each household every ten years - as has traditionally been the case. This survey would be broadly similar to the last census, but would primarily be completed online, at an estimated cost of $£ 625$ million (US\$1 billion) per decade.

The first, more-radical, proposal would produce a less exhaustive census, because only about half the population would be surveyed over ten years. It would also be cheaper, at $£ 460$ million per decade.

"There's a choice between detail once a decade, and more frequent statistics every year, but with less detail," says Peter Benton, the ONS official who is leading preparations for the next census, due in 2021. "They do have different strengths and weaknesses."

\section{Level of detail}

Benton says that the proposed yearly partial census would contain coarser information than the current system, which provides a level of detail that goes down to sets of as few as 300 people, known as output areas.

Some people are worried about this option.

Nigel Walford, a geography researcher at Kingston University in Kingston upon Thames, UK, who has long worked with census data, says that he has concerns: "It's not just an emotional attachment [to the current system]. For many researchers we don't want just the larger-scale data." 
$\mathrm{He}$ adds that data at the level of output areas can be useful — not just for researchers, but also for allocating local resources, such as council spending on care for older people. "We do want to know what's going on at that level," he says.

Several countries have updated how they run their censuses in recent years. But the changes have caused concern among some academics. In 2010, statistician Stephen Fienberg of Carnegie Mellon University in Pittsburgh, Pennsylvania, and political scientist Kenneth Prewitt of Columbia University in New York, warned that "census-taking around the world is under assault, thanks to concerns about privacy, cost and response rates" in a Comment article in Nature ${ }^{1}$.

Benton and the ONS stress that no decision has been taken yet. Any future census would also have to be agreed by the government and Parliament. The consultation opened today runs until 13 December, with the ONS hoping to publish its findings in 2014. The decision will apply to England and Wales. Scotland and Northern Ireland, which are partially self-governing entities within the United Kingdom, will each decide how to run the census within their boundaries.

"Different people have different views even within the academic community," says Benton. "We're seeking as part of the consultation to get views from people about the strengths and weaknesses."

Nature I doi:10.1038/nature.2013.13797

\section{References}

1. Fienberg, S. \& Prewitt, K. Nature 466, 1043 (2010) 